\title{
Evaluation of microsatellites for common ungulates in the South African wildlife industry
}

\author{
Susan M Miller ${ }^{\mathrm{a}, \mathrm{b}^{*}}$, Amy B Clarke ${ }^{\mathrm{b}}$, Paulette Bloomer ${ }^{\mathrm{a}}$, Alan J. Guthrie ${ }^{\mathrm{c}}$, Cindy K Harper ${ }^{\mathrm{b}}$ \\ ${ }^{a}$ Molecular Ecology and Evolution Program, Department of Genetics, University of Pretoria \\ ${ }^{b}$ Veterinary Genetics Laboratory, Faculty of Veterinary Science, University of Pretoria \\ ${ }^{c}$ Equine Research Centre, Faculty of Veterinary Science, University of Pretoria \\ *corresponding author: email: dangerousfrizbee@gmail.com; telephone: +27 12529 8240; facsimile: +27 12529 \\ 8310
}

\begin{abstract}
Wildlife is a multi-million dollar industry in South Africa ranging from intensively farmed animals on small properties to free-roaming animals in large functional ecosystems. Specific concerns surrounding the conservation value of the intensively managed wildlife have been raised. Increasingly it is recognised that genetics must be considered when developing conservation policy and management practices. Minimal genetic data are available to assist with decisions within the industry. Microsatellite markers have been developed for some species and are currently used for individual identification, parentage assessment and to inform translocation decisions. However, validation for standardized application in wildlife management has not been completed. Common species for which conservation management decisions have to be made include: Cape buffalo (Syncerus caffer), blue wildebeest (Connochaetes taurinus taurinus), common impala (Aepyceros melampus) and sable antelope (Hippotragus niger). Using existing microsatellite markers for domestic and wild species, we have developed multiplex panels for use in these species. We discriminated between 751 buffalo (four pairs were not distinguishable), 1307 blue wildebeest (three pairs were not distinguishable), 580 impala and 493 sable antelope. We determined parentage in four case studies using a combination of microsatellite and demographic data. We also tested microsatellite markers on roan antelope (Hippotragus equinus), gemsbok (Oryx gazella) and eland (Tragelaphus oryx) and report preliminary data. Further research to improve this validation includes: extensive sampling from more diverse areas, targeted or full genome sequencing to identify additional microsatellite loci, development of sampling kits and training of veterinarians, as well as expansion of the species tested.
\end{abstract}

Keywords: conservation genetics; microsatellite markers; ungulates; standardisation; South Africa

\section{Acknowledgements}

SMM was partially funded by a Post-doctoral Fellowship from the Faculty of Natural \& Agricultural Sciences of the University of Pretoria. 


\section{Introduction}

Wildlife is a multi-million dollar industry in South Africa (ABSA 2016). Over 18 million head of game are found on over 12000 privately owned wildlife ranches (Thomas 2013) and there are many more on both public and private reserves. The industry includes hunting for meat, eco-tourism and trophy hunting, including a rapidly expanding rare game and colour variant market. Animals are bought and sold at private auctions, some fetching hundreds of thousands of dollars. This top end of the industry routinely uses genetic testing as an identification tool and for parentage assignment (pers. obs. authors). Microsatellite loci are used to produce a unique DNA profile for each animal which is used in analyses. While single-nucleotide polymorphism (SNP) panels have been developed for parentage in some domestic species (e.g. cow (Bos taurus; Heaton et al. 2002) and sheep (Ovis aries; Heaton et al. 2014)), microsatellite markers are still the gold standard for forensic identification (SWGWILD 2012) and parentage analysis (Jones et al. 2010).

Although the game ranch industry is of economic benefit to South Africa, there are concerns that the intensive breeding for physical characteristics may be harming the conservation reputation of South Africa (SA Hunters and Game Conservation Association 2015; IUCN/SSC Antelope Specialist Group 2015). Even before the colour variant market developed, there were concerns that the genetic implications of game farming had not been addressed (Luxmoore 1985). Grobler \& Van der Bank (1994) found decreased diversity in two impala populations with few founders and no genetic management, compared to two populations with more founders and larger population sizes. They commented that many farmers did not take genetics into account when managing their populations. Nothing much appears to have changed in the intervening years, with Lindsey et al. (2009) commenting on the lack of monitoring of the ecological impacts of game ranching and subsequent dearth of information with which to develop policy. This has led to the industry developing with inadequate regulations and limited conservation value (Lindsey et al. 2009). Genetic diversity is increasingly being recognised as an essential component of conservation policy development and management (Hoban et al. 2013a, b). Standardised microsatellite markers could be used for many analyses relating to conservation of both common and endangered antelope in South Africa.

Standardisation and optimisation of the microsatellite loci used for each species is critical for any laboratory providing DNA services to the industry and for addressing conservation concerns. This is especially true if any of the results are to be used in court cases (Ogden et al. 2009). Many microsatellite markers for domestic animals have been standardised by the International Society for Animal Genetics (ISAG) for forensic use (www.isag.us), however, ISAG has not been extended to wildlife species. General standards have been developed for forensic testing (SWGWILD 2012). Several laboratories have published standardised microsatellite markers for wildlife species including the Eurasian badger (Meles meles) (Ogden et al. 2008) and, in our laboratory, the black (Diceros bicornis) and white (Ceratotherium simum) rhinonoceros (Harper et al. 2013) and the African lion (Panthera leo) (Miller et al. 2014). 
Common species found on South African game ranches include: Cape buffalo (Syncerus caffer), blue wildebeest (Connochaetes taurinus taurinus), blesbok (Damaliscus pygargus phillipsi), common impala (Aepyceros melampus), sable antelope (Hippotragus niger), roan antelope (H. equinus), gemsbok (Oryx gazella) and eland (Tragelaphus oryx). Cow-specific microsatellites have been successfully used in buffalo (van Hooft et al. 1999; van Hooft et al. 2000). Some species-specific markers have been developed for impala (Huebinger et al. 2006) and wildebeest (Røed et al. 2011). We have developed microsatellite panels for all of the common game species listed above using a combination of the available primers developed for sheep, goat (Capra aegagrus hircus), cow, impala and wildebeest. We assessed these panels for both individual identification and parentage applications. These panels will also be useful for addressing other wildlife management concerns such as inbreeding, translocation desirability and hybridization (Hoban et al. 2013a, b).

\section{Methods and Materials}

Samples submitted for routine DNA genotyping from game ranches across southern Africa to the Veterinary Genetics Laboratory, University of Pretoria were used to develop and standardise the microsatellite panels for each species. Samples consisted of either EDTA blood, whole blood without

EDTA, tissue or hair. There is no standardised sampling method in the South African wildlife industry and thus we were reliant on the accurate sampling and labelling of samples by the owner/veterinarian. DNA was extracted using standard laboratory techniques as previously described in Miller et al. (2014). A total of 759 buffalo, 1313 blue wildebeest, 580 impala, 493 sable antelope, 49 roan antelope, 68 gemsbok and 61 eland were used.

Microsatellite markers were selected from similar species in the published literature and those used for standard forensic testing of domestic species by ISAG (Online Resource 1). The amelogenin marker developed in the cow (Grzybowski et al. 2006) was included in all tests for sex determination. Not all of the loci were used at the outset; some loci were added to increase the power of individual identification (Online Resource 1). The forward primers were labelled with 6-FAM ${ }^{\mathrm{TM}}$, NED ${ }^{\mathrm{TM}}, \mathrm{VIC}^{\mathrm{TM}}$ or $\mathrm{PET}^{\mathrm{TM}}$ dyes and almost all of the reverse primers were tailed to facilitate accurate genotyping (Brownstein et al. 1996; Applied Biosystems, Warrington, UK). Polymerase Chain Reactions (PCR) and electrophoresis were performed in multiplexes of $10 \mu \mathrm{l}$ reactions using the KAPA2G ${ }^{\text {TM Fast }}$ Multiplex PCR Kit (Kapa Biosystems, Cape Town, South Africa). Multiplexing was done to reduce sample handling, cost and time. The concentration of some primers was adjusted to optimise the peak signals (Online Resource 1). The amplification PCRs were performed on a GeneAmp® PCR System 9700 (Perkin Elmer, Midrand, Gauteng), 9800 Fast Thermal Cycler or Veriti 96well Thermal Cycler (Applied Biosystems) as follows: denaturation at $95^{\circ} \mathrm{C}$ for three minutes; thirty cycles of: $95^{\circ} \mathrm{C}$ for 15 seconds, multiplex-specific annealing temperature ranging from $60-65^{\circ} \mathrm{C}$ (Online Resource 1) for 30 seconds and $72^{\circ} \mathrm{C}$ of extension for 30 seconds; a final amplification at $72^{\circ} \mathrm{C}$ for 10 minutes. We repeated multiplex four for one set of 15 wildebeest samples with 20 second annealing and extension times within the 30 cycles to see if amplification of CT27Gnu improved. Electrophoresis was performed on a 3130x Genetic Analyzer (Applied Biosystems). Allele sizes were determined using 
STRand (Toonen et al. 2001) (http://www.vgl.ucdavis.edu/informatics/strand.php) with the GeneScan $^{\mathrm{TM}} 500$ LIZ® size standard (Applied Biosystems). Standard bins were set for each microsatellite marker for each species and reading rules developed. Allelic heights were required to be a minimum of $100 \mathrm{rfu}$.

\section{Statistics}

Summary statistics were calculated for each microsatellite marker by species: number and size range of alleles and amplification success were calculated using Cervus v. 3.03 (Kalinowski et al. 2007). Allelic richness was calculated using FSTAT v 2.9.3.2 (Goudet 1995). A representative subset of wildebeest, buffalo, impala and sable antelope genotypes (taken from the different wildlife ranches to reduce relatedness bias) were used in Cervus to calculate: polymorphic information content (PIC) and observed versus expected heterozygosity. The "Probability test" option in the Hardy Weinberg test in Genepop (Rousset 2008) was used to calculate Hardy Weinberg Equilibrium (HWE) and the Bonferroni correction was applied (Rice 1989), as well as the less conservative modified false discovery rate (B-Y FDR) (Narum 2006). There were not enough samples to subsample roan antelope, gemsbok and eland. As the samples came from a limited number of herds we did not do any further analyses with these samples as relatedness bias could be too high.

Loci that had a significant deviation from HWE were discarded from further analyses after confirmation that they were not sex-linked. In one case, the TGLA263 locus in impala, dye and multiplex changes were made and we were able to reanalyse this locus for HWE. The reasons for other HWE deviations were explored and where possible, measures were taken to address them for future studies. The remaining loci were ranked from highest to lowest PIC value. Match probabilities for identity, identity of siblings and exclusion probabilities were then calculated cumulatively using the "Multilocus" function in the GenAIEx macro v. 6.501 for Microsoft Excel (Peakall et al. 2006).

\section{Parentage validation case studies}

We evaluated the applicability of the optimised microsatellite markers in parentage assessment case studies for each species. Due to the nature of wildlife ranches, mating events are rarely observed and thus there is no proof that the expected male is indeed the father of any offspring. In several cases where there was only one "stud male" on a wildlife ranch, genetic testing has revealed more than one father (pers. obs. authors). Maternity is more easily determined as most young are seen with their mother soon after birth, although this is not always the case and often these data are not recorded. In the case studies presented here, some of the samples were submitted with suspected parents based on observations by the owners.

We used Cervus to analyse multi-locus genotypes as recommended by Jones et al. (2010) to confirm or refute the observations of the owners. We have not reported the actual farms or animals to protect confidential information. In all cases, the genotypes for each individual case were used to generate allele frequencies. Simulations were based on the known information of each case. Sexes were confirmed with results from the amelogenin sexing marker where possible and genotypes of 
suspected parents separated accordingly. For impala and eland, the sex provided with the sample was used as the amelogenin sex marker did not amplify reliably. Confidence levels in the simulations were calculated using LOD scores with $80 \%$ (relaxed) and 95\% (strict) levels. The parentage analysis "parent pair, sexes known" function was used. All mismatches between expected and inferred parentages were confirmed manually. In cases where there was more than one parent pair found, further information was requested from the owner regarding the plausibility of the various results (e.g. more information on ages and physical location of the animals) and LOD scores were also examined. The details of each case are outlined in Table 1.

Table 1. Details of parentage cases and simulation parameters for Cervus.

\begin{tabular}{|c|c|c|c|c|c|c|c|c|c|c|}
\hline \multicolumn{6}{|c|}{ Samples submitted } & \multicolumn{5}{|c|}{ Simulation } \\
\hline Species & $\begin{array}{l}\text { Loci } \\
\text { used }\end{array}$ & $\begin{array}{l}\text { Min. } \\
\text { loci } \\
\text { typed }\end{array}$ & $\begin{array}{l}\text { Offspring } \\
\text { genotypes }\end{array}$ & $\begin{array}{l}\text { Female } \\
\text { genotypes }\end{array}$ & $\begin{array}{l}\text { Male } \\
\text { genotypes }\end{array}$ & Offspring & $\begin{array}{l}\text { Candidate } \\
\text { mothers }\end{array}$ & $\begin{array}{l}\text { Prop. } \\
\text { sampled }\end{array}$ & $\begin{array}{l}\text { Candidate } \\
\text { fathers }\end{array}$ & $\begin{array}{l}\text { Prop. } \\
\text { sampled }\end{array}$ \\
\hline $\begin{array}{l}\text { Sable } \\
\text { antelope }\end{array}$ & 8 & 6 & 9 & 71 & 30 & 10000 & 70 & 0.90 & 30 & 0.90 \\
\hline Wildebeest & 11 & 8 & 12 & 9 & 3 & 10000 & 9 & 0.50 & 3 & 0.50 \\
\hline Impala & 12 & 9 & 7 & 22 & 9 & 10000 & 22 & 0.50 & 9 & 0.90 \\
\hline Buffalo & 13 & 10 & 6 & 5 & 4 & 10000 & 5 & 0.50 & 4 & 0.70 \\
\hline
\end{tabular}

Cape buffalo: Samples from six offspring, four adult males and five adult females were submitted. We were asked to determine if any of the adults were parents of the offspring. All offspring were of the same age.

Blue wildebeest: Twenty six wildebeest samples were submitted with age and sex classes. The owner asked for parents of 14 offspring from nine possible females and three possible males.

Impala: Samples of impala were collected from a breeding camp with approximately 50 ewes and only one adult male. The owner wanted confirmation that one of the lambs was the offspring of a specific mother and the adult male. There was a second lamb that may have been the offspring if the first one was not. We did not sample all of the animals in the camp; we sampled 33 animals that included the suspected mother, the two lambs and the suspected father.

Sable antelope: One hundred and ten samples from sable antelope were submitted. Sex, but not age, was submitted with the samples. The owner asked for verification of parents of nine specific individuals. We used all the male and female genotypes available, including the suspected parents, to test for parents of the offspring.

\section{Results}

Locus statistics for each species are summarised in Table 2. One locus, 1701, was found to be sexlinked in impala and eland and was not included in further calculations. Amplification success was above 90 percent for most of the markers (Table 2). A few, such as D5S2 and I206 in impala and ILSTS19 and CT03Gnu in sable antelope had lower amplification success rates (Table 2). The 
Table 2. Microsatellite descriptive statistics and recommendations for use (or exclusion) in identification and parentage analyses for impala, buffalo, sable antelope and wildebeest. $N_{\mathrm{A}}$ - number of alleles; Amp amplification success; AR - allelic richness; PIC - Polymorphic Information Content; $H_{O}$ - observed heterozygosity; $P_{\mathrm{IDsibs}}$ cumulative - probability of identity of siblings; $-P_{\mathrm{ID}}$ cumulative - probability of identity; $P_{\mathrm{EXL}}$ one parent missing - Probability of exclusion with one parent missing

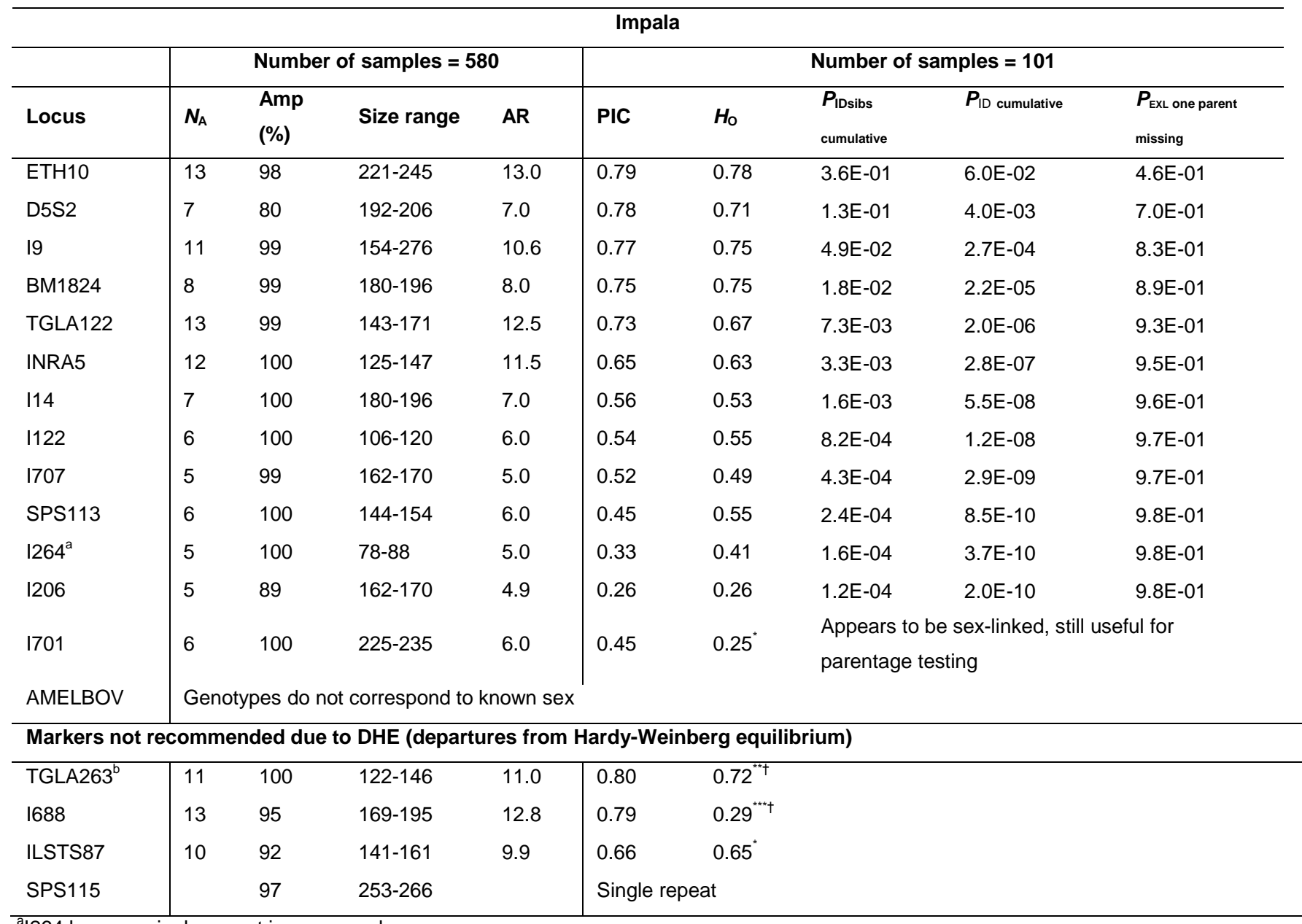

${ }^{\mathrm{a}}$ I264 has one single repeat in one sample

${ }^{\mathrm{b}}$ TGLA263 has since been moved to Multiplex 4 and the dye changed to VIC. Amplification has improved and it is now in HWE based on 94 unrelated samples with an $\mathrm{H}_{\mathrm{O}}$ of 0.87 and $\mathrm{PIC}$ of 0.85 .

" $P<0.1 ; "{ }^{* *}<0.01 ;{ }^{* * *} P<0.001$ significant Hardy-Weinberg deviation after Bonferroni correction (Rice 1989).

${ }^{\dagger} \underline{S}$ ignificant Hardy-Weinberg deviation after modified False Discovery Rate (FDR) correction, $\alpha=0.05$ (Narum 2006). 


\begin{tabular}{|c|c|c|c|c|c|c|c|c|c|}
\hline \multicolumn{10}{|c|}{ Buffalo } \\
\hline \multirow[b]{2}{*}{ Locus } & \multicolumn{4}{|c|}{ Number of samples $=759$} & \multicolumn{5}{|c|}{ Number of samples $=144$} \\
\hline & $N_{A}$ & $\begin{array}{l}\text { Amp } \\
\text { (\%) }\end{array}$ & Size range & AR & PIC & $H_{O}$ & $\begin{array}{l}P_{\text {IDsibs }} \\
\text { cumulative }\end{array}$ & $P I_{\text {cumulative }}$ & $\begin{array}{l}\boldsymbol{P}_{E X L} \text { one parent } \\
\text { missing }\end{array}$ \\
\hline DIK020 & 19 & $26^{a}$ & $173-217$ & 18.9 & 0.88 & 0.91 & $3.1 \mathrm{E}-01$ & $2.2 \mathrm{E}-02$ & $6.3 \mathrm{E}-01$ \\
\hline BM1824 & 15 & 100 & $175-211$ & 14.4 & 0.87 & 0.81 & 9.9E-02 & $6.0 \mathrm{E}-04$ & 8.6E-01 \\
\hline BM3205 & 15 & 99 & $208-236$ & 13.7 & 0.85 & 0.83 & $3.2 \mathrm{E}-02$ & 2.0E-05 & $9.4 \mathrm{E}-01$ \\
\hline SPS115 & 15 & 97 & $229-259$ & 14.4 & 0.81 & 0.78 & $1.1 \mathrm{E}-02$ & $9.9 \mathrm{E}-07$ & 9.7E-01 \\
\hline ILSTS026 & 12 & 99 & $153-177$ & 11.0 & 0.80 & 0.79 & 4.0E-03 & 4.9E-08 & $9.8 \mathrm{E}-01$ \\
\hline BM1818 & 12 & 99 & $269-297$ & 11.9 & 0.79 & 0.83 & $1.4 \mathrm{E}-03$ & 2.7E-09 & $9.9 \mathrm{E}-01$ \\
\hline ILSTS028 & 22 & 99 & $249-307$ & 20.6 & 0.79 & 0.64 & $5.2 \mathrm{E}-04$ & $1.5 \mathrm{E}-10$ & $1.0 \mathrm{E}+00$ \\
\hline CSSM19 & 13 & 98 & $136-164$ & 12.3 & 0.73 & 0.70 & $2.0 \mathrm{E}-04$ & $1.3 \mathrm{E}-11$ & $1.0 \mathrm{E}+00$ \\
\hline INRA006 & 10 & 99 & $109-127$ & 8.8 & 0.73 & 0.68 & 8.0E-05 & $1.2 \mathrm{E}-12$ & $1.0 \mathrm{E}+00$ \\
\hline TGLA263 & 8 & 97 & $122-140$ & 7.5 & 0.64 & 0.67 & 3.5E-05 & 1.7E-13 & $1.0 \mathrm{E}+00$ \\
\hline BM3517 & 7 & 99 & $94-106$ & 6.7 & 0.54 & 0.53 & $1.8 \mathrm{E}-05$ & 3.7E-14 & $1.0 \mathrm{E}+00$ \\
\hline TGLA227 & 4 & 100 & $74-80$ & 4.0 & 0.32 & 0.29 & 1.3E-05 & $1.7 \mathrm{E}-14$ & $1.0 \mathrm{E}+00$ \\
\hline ETH10 & 5 & 99 & $202-210$ & 4.0 & 0.27 & 0.31 & $9.1 \mathrm{E}-06$ & $8.6 \mathrm{E}-15$ & $1.0 \mathrm{E}+00$ \\
\hline AMELBOV & 2 & 99.6 & 214,284 & - & Sexin & arker & & & \\
\hline \multicolumn{10}{|c|}{ Markers not recommended due to DHE } \\
\hline BM719 & 15 & 100 & $136-170$ & 14.4 & 0.86 & $0.78^{* x+}$ & & & \\
\hline CSRM60 & 15 & $26^{\mathrm{a}}$ & $92-140$ & 15.0 & 0.82 & $0.39^{* * *+}+$ & & & \\
\hline TGLA159 & 10 & 98 & $223-245$ & 8.4 & 0.75 & $0.71^{*}+$ & & & \\
\hline TGLA057 & 10 & 99 & $87-113$ & 8.4 & 0.74 & $0.64^{* *}+$ & & & \\
\hline BM4028 & 9 & 100 & $134-160$ & 8.0 & 0.41 & $0.35^{* \dagger}$ & & & \\
\hline
\end{tabular}

${ }^{a}$ Success rate in the last 100 samples is up to 94 and 86 percent respectively with new panels

" $\mathrm{P}<0.1$; "* $\mathrm{P}<0.01$; "** $\mathrm{P}<0.001$ significant Hardy-Weinberg deviation after Bonferroni correction (Rice 1989).

${ }^{\dagger} \underline{S}$ ignificant Hardy-Weinberg deviation after modified False Discovery Rate (FDR) correction, $\alpha=0.05$ (Narum 2006).

\begin{tabular}{|c|c|c|c|c|c|c|c|c|c|}
\hline \multicolumn{10}{|c|}{ Sable Antelope } \\
\hline \multirow[b]{2}{*}{ Locus } & \multicolumn{4}{|c|}{ Number of samples $=493$} & \multicolumn{5}{|c|}{ Number of samples $=60$} \\
\hline & $N_{\mathrm{A}}$ & $\begin{array}{l}\text { Amp } \\
(\%)\end{array}$ & Size range & AR & PIC & $H_{0}$ & $\begin{array}{l}P_{\text {IDsibs }} \\
\text { cumulative }\end{array}$ & $P_{\mathrm{ID} \text { cumulative }}$ & $\boldsymbol{P}_{\text {EXL one parent missing }}$ \\
\hline ILSTS87 & 11 & 95 & $151-171$ & 11.0 & 0.85 & 0.75 & $3.3 E-01$ & $3.3 E-02$ & $5.7 E-01$ \\
\hline CT07Gnu & 14 & 95 & $95-137$ & 13.6 & 0.83 & 0.80 & 1.1E-01 & $1.3 \mathrm{E}-03$ & 8.0E-01 \\
\hline ILSTS19 & 24 & 81 & $162-230$ & 23.0 & 0.82 & 0.76 & 3.8E-02 & $5.6 \mathrm{E}-05$ & $9.0 \mathrm{E}-01$ \\
\hline CSSM19 & 9 & 99 & $143-163$ & 8.6 & 0.81 & 0.75 & 1.3E-02 & 2.9E-06 & $9.5 \mathrm{E}-01$ \\
\hline CT10Gnu & 11 & 94 & $107-129$ & 10.9 & 0.78 & 0.68 & $4.8 \mathrm{E}-03$ & $1.9 \mathrm{E}-07$ & 9.7E-01 \\
\hline SPS113 & 12 & 99 & $150-174$ & 10.9 & 0.74 & 0.65 & $1.9 \mathrm{E}-03$ & 1.6E-08 & 9.8E-01 \\
\hline D5S2 & 8 & 99 & $208-222$ & 8.0 & 0.74 & 0.72 & 7.2E-04 & 1.4E-09 & $9.9 \mathrm{E}-01$ \\
\hline CT03Gnu & 12 & 59 & $103-125$ & 12.0 & 0.72 & 0.64 & $2.9 \mathrm{E}-04$ & $1.4 \mathrm{E}-10$ & $9.9 \mathrm{E}-01$ \\
\hline TGLA263 & 12 & 99 & $103-157$ & 10.8 & 0.58 & 0.60 & $1.4 \mathrm{E}-04$ & $2.6 \mathrm{E}-11$ & $9.9 \mathrm{E}-01$ \\
\hline SRCRSP24 & 5 & 96 & $154-174$ & 4.6 & 0.50 & 0.60 & 7.3E-05 & $6.5 \mathrm{E}-12$ & $1.0 \mathrm{E}+00$ \\
\hline BM2113 & 8 & 100 & $127-157$ & 7.2 & 0.47 & 0.57 & 4.1E-05 & $1.8 \mathrm{E}-12$ & $1.0 \mathrm{E}+00$ \\
\hline ETH10 & 3 & 96 & $203-207$ & 3.0 & 0.09 & 0.10 & 3.7E-05 & $1.5 \mathrm{E}-12$ & $1.0 \mathrm{E}+00$ \\
\hline AMELBOV & 2 & 95 & 217,258 & & Sexir & & & & \\
\hline
\end{tabular}




\begin{tabular}{l|llll|ll}
\hline BMS4008 & 10 & 87 & $168-186$ & 10.0 & 0.80 & $0.57^{* * *} \dagger$ \\
CT13Gnu & 11 & 99 & $160-194$ & 10.2 & 0.76 & $0.73^{* \dagger}$ \\
BM719 & 10 & 99 & $149-181$ & 9.3 & 0.69 & $0.55^{* * \dagger}$ \\
\hline
\end{tabular}

$\mathrm{P}<0.1 ; " \mathrm{P}<0.01 ; " \mathrm{P}<0.001$ significant Hardy-Weinberg deviation after Bonferroni correction (Rice 1989).

${ }^{\dagger}$ Significant Hardy-Weinberg deviation after modified False Discovery Rate (FDR) correction, $\alpha=0.05$ (Narum 2006).

\begin{tabular}{|c|c|c|c|c|c|c|c|c|c|}
\hline \multirow[b]{3}{*}{ Locus } & \multicolumn{8}{|c|}{ Wildebeest } & \\
\hline & \multicolumn{4}{|c|}{ Number of samples $=1313$} & \multicolumn{5}{|c|}{ Number of samples $=\mathbf{2 7 7}$} \\
\hline & $N_{\mathrm{A}}$ & $\begin{array}{l}\text { Amp } \\
\text { (\%) }\end{array}$ & Size range & AR & PIC & $H_{0}$ & $\begin{array}{l}P_{\text {IDsibs }} \\
\text { cumulative }\end{array}$ & $\boldsymbol{P}_{\mathrm{ID} \text { cumulative }}$ & $\begin{array}{l}\boldsymbol{P}_{\text {EXL one parent }} \\
\text { missing }\end{array}$ \\
\hline CT12Gnu & 18 & 99 & $112-154$ & 17.6 & 0.90 & 0.87 & $3.0 \mathrm{E}-01$ & $1.6 \mathrm{E}-02$ & $6.8 \mathrm{E}-01$ \\
\hline CT10Gnu & 21 & 99 & $101-145$ & 20.3 & 0.88 & 0.85 & $9.4 \mathrm{E}-02$ & $3.8 \mathrm{E}-04$ & 8.8E-01 \\
\hline ILSTS19 & 15 & 100 & $150-186$ & 14.7 & 0.84 & 0.82 & 3.1E-02 & 1.5E-05 & $9.5 \mathrm{E}-01$ \\
\hline CT08Gnu & 17 & 100 & $90-130$ & 16.5 & 0.83 & 0.78 & 1.1E-02 & 5.7E-07 & 9.7E-01 \\
\hline BMS4008 & 30 & 96 & $216-346$ & 28.6 & 0.81 & 0.78 & 3.7E-03 & 2.7E-08 & $9.9 \mathrm{E}-01$ \\
\hline CT19Gnu & 8 & 95 & $188-200$ & 8.0 & 0.78 & 0.79 & $1.4 \mathrm{E}-03$ & $1.8 \mathrm{E}-09$ & $9.9 \mathrm{E}-01$ \\
\hline SRCRSP24 & 11 & 99 & $147-173$ & 10.7 & 0.77 & 0.77 & 5.1E-04 & $1.2 \mathrm{E}-10$ & $1.0 \mathrm{E}+00$ \\
\hline BM719 & 9 & 93 & $128-160$ & 8.9 & 0.72 & 0.73 & $2.0 \mathrm{E}-04$ & $1.2 \mathrm{E}-11$ & $1.0 \mathrm{E}+00$ \\
\hline BM2113 & 6 & 99 & $131-145$ & 6.0 & 0.50 & 0.49 & 1.1E-04 & $2.9 \mathrm{E}-12$ & $1.0 \mathrm{E}+00$ \\
\hline CT03Gnu & 4 & 100 & $91-101$ & 4.0 & 0.34 & 0.37 & 7.3E-05 & $1.2 \mathrm{E}-12$ & $1.0 \mathrm{E}+00$ \\
\hline CT30Gnu & 7 & 99 & $101-125$ & 6.7 & 0.13 & 0.14 & 6.4E-05 & $9.5 \mathrm{E}-13$ & $1.0 \mathrm{E}+00$ \\
\hline AMELBOV & 2 & 100 & 214,258 & & Sexil & & & & \\
\hline
\end{tabular}

Markers not recommended for parentage due to DHE or excessive stutter

\begin{tabular}{l|cccc|ll}
\hline CT27Gnu & 39 & 89 & $105-181$ & 38.1 & 0.94 & 0.86 \\
CT07Gnu & 14 & 95 & $101-139$ & 13.7 & 0.87 & $0.72^{* *} \dagger$ \\
D5S2 & 14 & 99 & $196-232$ & 13.9 & 0.83 & $0.82^{* *} \dagger$ \\
CT13Gnu & 19 & 95 & $146-188$ & 18.9 & 0.79 & $0.72^{* * \star}+$ \\
BM1824 & 11 & 78 & $168-216$ & 10.8 & 0.74 & $0.57^{* * \star} \dagger$ \\
FCB20 & 13 & 95 & $84-124$ & 13.0 & 0.72 & $0.56^{* * *}+$ \\
\hline
\end{tabular}

$\mathrm{P}<0.1$; " $\mathrm{P}<0.01$; " $\mathrm{P}<0.001$ significant Hardy-Weinberg deviation after Bonferroni correction (Rice 1989).

${ }^{\dagger}$ significant Hardy-Weinberg deviation after modified False Discovery Rate (FDR) correction, $\alpha=0.05$ (Narum 2006).

\begin{tabular}{lllll}
\hline & \multicolumn{4}{c}{ Roan; Number of samples $=\mathbf{4 9}$} \\
Locus & $\boldsymbol{N}_{\boldsymbol{A}}$ & Amp (\%) & Size range & Comments \\
\hline BM2113 & 8 & 100 & $135-159$ & \\
BM719 & 7 & 100 & $155-183$ & \\
BMS4008 & 9 & 100 & $164-196$ & \\
CSSM19 & 9 & 100 & $143-160$ & Single repeats \\
CT03Gnu & 14 & 98 & $107-147$ & \\
CT07Gnu & 17 & 94 & $103-159$ & Excessive stutter \\
CT10Gnu & 11 & 100 & $101-141$ & \\
CT13Gnu & 16 & 100 & $162-216$ & \\
D5S2 & 4 & 98 & $200-216$ & \\
ETH10 & 5 & 90 & $201-209$ & \\
ILSTS19 & 7 & 94 & $164-196$ & \\
ILSTS87 & 9 & 100 & $157-177$ & \\
SPS113 & 6 & 100 & $146-166$ &
\end{tabular}




\begin{tabular}{lllll} 
SRCRSP24 & 6 & 98 & $162-174$ & \\
TGLA263 & 13 & 100 & $103-185$ & \\
AMELBOV & 2 & 100 & 217,258 & Sexing marker \\
\hline
\end{tabular}

Eland; Number of samples $=68$

\begin{tabular}{lllll} 
Locus & $\boldsymbol{N}_{\boldsymbol{A}}$ & Amp (\%) & Size range & Comments \\
\hline BM719 & 18 & 94 & $156-183$ & Single repeats \\
CT10Gnu & 4 & 100 & $107-113$ & \\
D5S2 & 16 & 99 & $210-246$ & Possible base pair insertion between 219 and 222 \\
ETH10 & 7 & 97 & $208-220$ & \\
I122 & 11 & 100 & $118-141$ & \\
I7 & 6 & 99 & $109-125$ & \\
I701 & 12 & 100 & $200-271$ & Sex-linked; possible base pair insertion between 258 and 261 \\
ILSTS19 & 7 & 97 & $155-171$ & \\
ILSTS87 & 6 & 96 & $122-134$ & \\
INRA006 & 13 & 66 & $110-134$ & \\
INRA5 & 12 & 100 & $123-149$ & \\
SPS113 & 10 & 100 & $140-158$ & Possible base pair insertion between 206 and 213 \\
SRCRSP5 & 7 & 99 & $194-215$ & Did not amplify successfully \\
AMELBOV & & & & \\
\hline
\end{tabular}

\begin{tabular}{lllll}
\hline & \multicolumn{4}{c}{ Gemsbok; Number of samples = 61 } \\
Locus & $\boldsymbol{N}_{\boldsymbol{A}}$ & Amp (\%) & Size range & Comments \\
\hline BM2113 & 14 & 98 & $127-165$ & \\
BM719 & 3 & 100 & $159-163$ & \\
BMS4008 & 12 & 100 & $162-194$ & \\
CSSM19 & 2 & 100 & $156-158$ & \\
CSSM66 & 4 & 100 & $169-175$ & \\
CT10Gnu & 8 & 100 & $107-133$ & \\
D5S2 & 14 & 100 & $199-235$ & Excessive stutter \\
ETH3 & 4 & 100 & $106-110$ & Single repeat \\
I707 & 10 & 84 & $174-196$ & \\
ILSTS19 & 6 & 75 & $156-182$ & \\
ILSTS87 & 7 & 56 & $142-160$ & \\
SPS113 & 8 & 98 & $164-196$ & \\
SPS115 & 3 & 98 & $254-260$ & \\
TGLA263 & 3 & 100 & $130-142$ & Sexing marker \\
AMELBOV & 2 & 100 & 217,258 & \\
\hline
\end{tabular}

amplification success of the two impala markers has improved in recent months while that of the sable antelope markers is still not ideal (data not shown). Table 3 is a summary of the number of loci in HWE, average allelic richness and the power of these microsatellite markers to discriminate between individuals and siblings compared to the estimated population sizes of these species. 
Table 3. Summary of the power of the microsatellite marker panels to discriminate between individuals compared to estimated numbers of each species found in the game ranch industry. HWE - Hardy Weinberg Equilibrium; AR - Allelic Richness; SA - South Africa

\begin{tabular}{|c|c|c|c|c|c|}
\hline & & & \multicolumn{2}{|c|}{ Identification } & Populations \\
\hline Species & $\begin{array}{c}\text { No. loci in } \\
\text { HWE }\end{array}$ & $\begin{array}{c}\text { Av. AR per } \\
\text { locus }\end{array}$ & Individuals & Siblings & $\begin{array}{c}\text { SA game } \\
\text { ranches }\end{array}$ \\
\hline Cape buffalo & 13 & 11.4 & $1.2 \times 10^{14}$ & $1.1 \times 10^{5}$ & $6 \times 10^{5}$ \\
\hline $\begin{array}{l}\text { Blue } \\
\text { wildebeest }\end{array}$ & 11 & 12.9 & $1.1 \times 10^{12}$ & $1.6 \times 10^{4}$ & $1 \times 10^{5}$ \\
\hline $\begin{array}{l}\text { Common } \\
\text { impala }\end{array}$ & $\begin{array}{c}12+1 \text { sex } \\
\text { linked }^{*}\end{array}$ & 8.0 & $4.9 \times 10^{9}$ & $8.2 \times 10^{3}$ & $2 \times 10^{6}$ \\
\hline $\begin{array}{l}\text { Sable } \\
\text { antelope }\end{array}$ & 12 & 10.3 & $6.8 \times 10^{11}$ & $2.7 \times 10^{4}$ & $2 \times 10^{5}$ \\
\hline
\end{tabular}

${ }^{*}$ Sex-linked locus not included in calculations;

†Rough estimates as no official numbers are available (pers. comm. P. Oberem, March 2015)

In Cape buffalo 13 of 18 optimized microsatellite loci were in HWE (Table 2). The microsatellite markers in HWE allowed for individual identification of all the samples in our dataset (Table 2), except for three pairs of animals (data not shown). These pairs of animals matched at all amplified loci, however, DIK020 did not amplify successfully in at least one of each pair.

In blue wildebeest 12 microsatellite loci were in HWE and five deviated significantly. While CT27Gnu was the most variable microsatellite marker and in HWE, the larger alleles were prone to excessive stutter preventing accurate scoring of these alleles (Fig. 1). A reduction in annealing and extension times in the cycles of the PCR did not alter the amount of stutter. Thus, this microsatellite marker was not used in further analyses. Using the remaining microsatellite markers that were in HWE, we were able to discriminate between all of the subset of individuals. Theoretically these microsatellite markers could distinguish between $1.1 \times 10^{12}$ individuals or $1.6 \times 10^{4}$ related animals. However, we were not able to discriminate between the 1313 individuals in our larger dataset. There were still nine pairs of samples with matching genotypes.

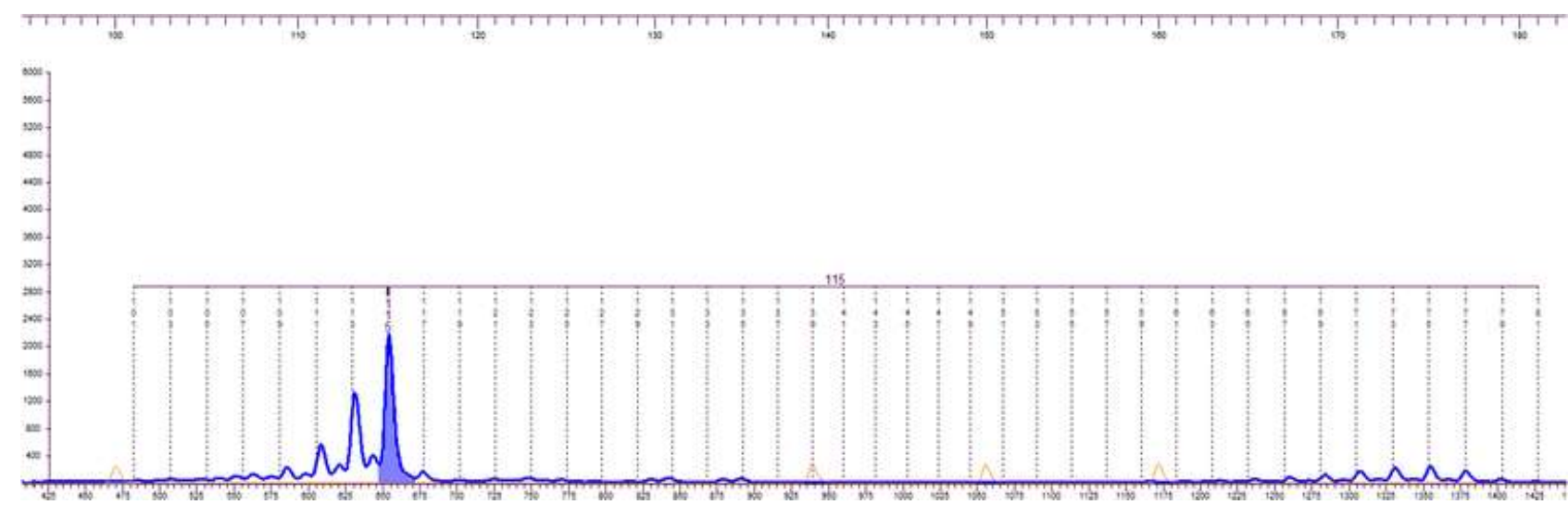

Fig. 1. Electropherogram of CT27Gnu in a blue wildebeest sample showing excessive stutter at the larger allele size 
In impala 12 microsatellite loci were in HWE and four deviated from HWE, of which one appeared to be sex-linked (Table 2). One microsatellite locus appeared to have a single repeat motif, making accurate scoring impossible (Table 2). As indicated in the materials and methods, the TGLA263 locus appeared not to be amplifying properly in multiplex 3 . We have since moved it to multiplex 4 and changed the colour to VIC and it is now in HWE (Table 2). D5S2 and 1206 were not amplifying reliably, following the removal of 1688 from panel 1 and SPS115 from panel 4, these two markers are now amplifying reliably (data not shown). The amelogenin sexing marker failed to amplify with any correlation to the sex of the animals. We were able to discriminate between all of the individuals in our dataset using the microsatellite markers in HWE (Table 2).

In sable antelope 12 of 15 microsatellite loci were in HWE (Table 2). The microsatellite markers in HWE discriminated between all of the individuals in our study.

Roan antelope, eland and gemsbok allele size ranges and amplification successes are shown in Table 2. We have noted potential problems in individual microsatellite markers. The amelogenin sexing marker did not amplify in the eland.

\section{Parentage}

Overall the microsatellite markers were successful in assisting with determining the parentage of animals in the various case studies. There were some cases where observational and demographic data were needed to clarify the result when there was more than one possible parent. The results are summarised in Table 4.

Cape buffalo case study (Table 4): Of the six offspring submitted, two were assigned full parent pairs. The combined LOD scores were 14.7 and 8.7. Three of the offspring had no matching mother and one matching father, with no exclusions. LOD scores ranged from 0.50 to 3.1. The final offspring had no match for a mother or a father and only negative LOD scores.

Table 4: Case study results. Parentage analyses performed in Cervus. LOD (logarithm of the odds) scores for potential mothers, fathers and combinations of parents for selected offspring

\begin{tabular}{llll}
\hline Offspring & $\begin{array}{l}\text { Mother LOD } \\
\text { Score }\end{array}$ & $\begin{array}{l}\text { Father LOD } \\
\text { Score }\end{array}$ & $\begin{array}{l}\text { Combined } \\
\text { LOD Score }\end{array}$ \\
\hline Cape Buffalo & & & \\
\hline Calf 1 & 6.24 & 3.67 & 1.47 \\
Calf 2 & no match & 3.09 & n/a \\
Calf 3 & 2.30 & 2.11 & 8.70 \\
Calf 4 & no match & no match & n/a \\
Calf 5 & no match & 1.52 & n/a \\
Calf 6 & no match & 4.71 & n/a \\
\hline Blue wildebeest & & \\
\hline Calf 1 & no match & 1.66 & n/a \\
Calf 2 & 9.52 & 1.27 & 15.3 \\
Calf 3 & 4.35 & 2.88 & 10.6 \\
Calf 4 & 6.03 & no match & n/a \\
\hline
\end{tabular}




\begin{tabular}{|c|c|c|c|c|}
\hline Calf 5 & no match & 0.63 & $\mathrm{n} / \mathrm{a}$ & \\
\hline Calf 6 & 7.65 & 0.47 & 12.6 & \\
\hline Calf 7 & 4.67 & 2.58 & 11.3 & \\
\hline Calf 8 & no match & 2.07 & $\mathrm{n} / \mathrm{a}$ & \\
\hline Calf 9 & no match & 1.85 & $\mathrm{n} / \mathrm{a}$ & \\
\hline Calf 10 & no match & -0.08 & $\mathrm{n} / \mathrm{a}$ & \\
\hline Calf 11 & no match & 0.86 & $\mathrm{n} / \mathrm{a}$ & \\
\hline Calf 12 & 1.66 & 1.45 & -9.61 & 4 exclusions for parent pair \\
\hline Calf 13 & no match & 1.81 & $\mathrm{n} / \mathrm{a}$ & \\
\hline Calf 14 & no match & 1.82 & $\mathrm{n} / \mathrm{a}$ & \\
\hline \multicolumn{5}{|l|}{ Impala } \\
\hline \multirow[t]{2}{*}{ Lamb 1} & 1.46 & 2.81 & 8.80 & Both ewes a match with same ram, observational data \\
\hline & 1.67 & 2.81 & 7.45 & suggests first ewe is actual mother \\
\hline Lamb 2 & 3.12 & 0.21 & 0.42 & $\begin{array}{l}\text { No exclusions mother only, } 1 \text { exclusion father, } 2 \text { exclusions } \\
\text { combined }\end{array}$ \\
\hline \multicolumn{5}{|c|}{ Sable antelope } \\
\hline Calf 1 & 8.24 & 4.82 & 14.7 & \\
\hline \multirow[t]{3}{*}{ Calf 2} & 5.30 & 4.57 & 11.3 & \multirow{2}{*}{ Both possible mothers } \\
\hline & 3.06 & 4.57 & 9.90 & \\
\hline & 3.69 & 4.57 & 9.68 & Potential mother same age as calf so not possible \\
\hline \multirow[t]{2}{*}{ Calf 3} & 3.80 & 6.07 & 1.31 & \multirow{2}{*}{ Both possible mothers } \\
\hline & 3.11 & 6.07 & 1.24 & \\
\hline \multirow[t]{2}{*}{ Calf 4} & 15.4 & 6.71 & 21.5 & Potential mother same age as calf so not possible \\
\hline & 6.99 & 6.71 & 18.2 & Most likely mother \\
\hline Calf 5 & 5.42 & 6.20 & 16.5 & \\
\hline Calf 6 & 4.67 & 7.46 & 14.7 & \\
\hline Calf 7 & 6.87 & 5.27 & 15.2 & \\
\hline \multirow[t]{2}{*}{ Calf 8} & 15.4 & 6.71 & 21.5 & Most likely mother \\
\hline & 6.99 & 6.71 & 18.2 & Already assigned to Calf 4 \\
\hline Calf 9 & 5.11 & 5.85 & 13.5 & \\
\hline
\end{tabular}

Blue wildebeest case study (Table 4): Of the 14 offspring submitted, four were assigned full parent pairs with no exclusions. The combined LOD scores ranged from 10.6 to 15.3. Eight had no exclusions for one father each, with LOD scores ranging from -0.08 to 2.6. One had no exclusions for one mother with a LOD score of 6.0. The final offspring had one match for a mother (LOD of 1.7) and one match for a father (LOD of 1.4), but four exclusions as a pair (LOD score of -9.6 ).

Impala case study (Table 4): The suspected ewe and ram was a perfect match for the lamb as the owner predicted (combined LOD score of 7.4). There was one other ewe that was also a perfect match (with the same ram; combined LOD score 8.8). Two other rams matched with at least one of 
the ewes (all with positive LOD scores; data not shown). The second lamb had a perfect match with one ewe (LOD score 3.1) and one ram with one exclusion (LOD score 0.21). Combined, there were two exclusions and a combined LOD score of 0.42 . One exclusion was at ETH10 as all three samples were heterozygous at this locus. The other exclusion was at BM1824; the offspring was heterozygous $(184 / 188)$ and the two potential parents were both homozygous for allele 184.

Sable antelope case study (Table 4): Parentages of all nine offspring were confirmed with genetic testing. For five of the offspring only one set of parents was a perfect match (LOD scores ranging from 13.5 to 16.5$)$. In the other cases there were multiple candidate pairs with multiple mothers and only one candidate father. Of the offspring with multiple candidate mothers, some mothers were eliminated after more demographic information was obtained from the owner. A further candidate mother was eliminated as she was already the only possible mother for another offspring, leaving only one possible mother. For two offspring we were not able to confirm the mothers. Both offspring had the same two candidate mothers, however, there was no age data to assist with assignment.

\section{Discussion}

Multiplex microsatellite panels were evaluated for use in identification of Cape buffalo, blue wildebeest, impala and sable antelope. We recommend using all of the loci that were in HWE for identification purposes. Using these microsatellite markers we could theoretically distinguish between large numbers of animals in each species. However, in the game ranch industry one male is often used to breed with many females to pass on his desirable traits, resulting in many closely related offspring (pers. obs. authors). Using the more conservative probability of identity for related animals rather than that for unrelated animals to determine the power of microsatellite markers for identification as recommended by Waits et al. (2001) is thus more logical. More microsatellite markers are likely to be required to discriminate between animals in the future. In fact we already have a few cases in wildebeest where we are not able to discriminate between several pairs of individuals from one farm. This could be due to sampling error with two samples submitted from the same animal with different labels, but they could be genuine matches at all of our loci. There were also some buffalo where a highly informative microsatellite marker did not amplify and we were not able to discriminate between the individuals.

Parentage assignment analysis is more complicated than individual identity. Individual animals are used to breed against many females and often multiple generations of animals are kept in one herd. Owners often only send in samples from the offspring and a small selection of possible parents. This can complicate parentage analysis as highlighted by Jones et al. (2010). Furthermore only microsatellite markers in HWE should be used, as null alleles can severely affect parentage assignment (Pemberton et al. 1995). The case studies we presented were chosen to show the variety of requests that the laboratory receives and to highlight the challenges associated with them. Despite the statistical power of the microsatellite markers in all species, there were still several cases where observational and/or age data were required to interpret the genetic results. This reliance on a combination of observational and genetic data has been seen in dispersal studies as well (Harris et al. 
2009). In the impala case we were not able to definitively identify the mother as there was a second matching female of similar age. If we had sampled the entire herd, it is likely that we would have been able to determine the actual mother. Ideally we will add more microsatellite markers to be able to improve the genetic parentage testing in order to be less reliant on observational data. Harrison et al. (2013) recommend 20 or more polymorphic markers to reduce errors associated with microsatellite data. We also plan on improving collection of additional data, as age data were not available for all samples (see below).

For impala and wildebeest we used some microsatellite markers that were designed for these species (Huebinger et al. 2006; Røed et al. 2011). For the most part these loci were successful. There were some microsatellite markers that had problems with single repeats, significant deviations from HardyWeinberg Equilibrium and one was sex-linked with no indication of this in the original paper. The original papers outlining the blue wildebeest (Røed et al. 2011) and impala (Huebinger et al. 2006) microsatellite markers had limited numbers of samples from only one location. With our larger database from game farms across South Africa, we found alleles that were not in the original papers. We were better able to evaluate the usefulness of these microsatellite markers and some we have not recommended for use in South African animals. This highlights the need for diverse sampling when reporting on microsatellite markers for use in population studies and for testing of microsatellite markers before use on animals in a different geographic area from where they were originally designed.

The most polymorphic microsatellite marker designed for blue wildebeest was the least successful. Larger alleles did not amplify reliably, resulting in extreme stuttering where it was not possible to identify the actual allele from the stutter. Attempts to change the PCR conditions did not improve the reliability of scoring these alleles. Not being able to use the most polymorphic microsatellite marker may not have a significant impact. Bernatchez \& Duchesne (2000) showed that there is no significant gain in power beyond approximately six to ten alleles per locus for parentage assignment.

Some of the other markers also did not amplify reliably. Two of the impala markers have improved with the changes to the panels following the removal of two other markers (Online Resource 1). The amplification issues in sable still need to be addressed and if they cannot be resolved, we will have to consider removing these markers from the panels.

The amelogenin sexing marker that was designed for the cow (Grzybowski et al. 2006) worked well in most of the species tested here. It did not amplify correctly in the impala or the eland. There were peaks present in both species, however, they were not linked to the known sex of the animals. There may be a possibility of using a zinc finger marker to determine sex instead of the amelogenin sexing marker. Lindsay et al (2008) have developed a zinc finger test in white-tailed deer (Odocoileus virginianus), however, the sizes of the fragments were too large for standard fragment testing in microsatellite multiplexes. Development of a sexing marker for impala and eland warrants further investigation. 
Several of the microsatellite markers were not in Hardy-Weinberg equilibrium and thus we did not recommend them for use in forensic and/or parentage cases. These were both species-specific and cross-species microsatellite markers. We were able to improve the amplification of one microsatellite marker in impala by moving it from one multiplex to another and changing the dye. This emphasises the importance of careful multiplex design. For the others it is possible that despite careful selection of samples from within our dataset for these statistical tests, they were not diverse enough to rule out a relationship bias, particularly for the sable antelope where our sample size was smaller. This could only be tested with the acquisition of samples from an outbred population. As recommended by Selkoe et al. (2006) sequencing of some of the alleles where abnormalities occurred, as well as microsatellite markers with lower success rates, is warranted. Sequencing results could be of value to redesign primers that may be causing null alleles. If the null alleles can be eliminated, these markers would then be expected to be in HWE allowing them to be included in future analyses.

There were a few cases in our testing where we suspect there may have been sampling errors. There is currently no standardised method for sampling game animals in the field in South Africa. Our laboratory has developed a kit for sampling rhinoceros DNA and training courses have been presented on the proper use of the kits. An android app has also been developed for electronic data capture and direct uploading to the database at the laboratory to reduce errors. We are planning to expand this to include all common wildlife species. This should reduce sampling error in the future. It should also improve the collection of age and sex data which are often missing when samples are submitted. These data, as mentioned above, can be crucial in parentage assignment.

Most of the samples used in this study were from intensely managed populations. Expansion of sampling to include animals from commercial hunting operations where harvesting for meat is the primary objective may be of value to study less intensely managed populations. It would also be useful to incorporate samples collected from animals from open systems such as national parks and provincial nature reserves. These data would allow one to compare the population statistics for the intensely managed populations to the less intensely managed populations and open systems. These data could then be used to assist in conservation decisions relating to management and policy development as suggested by Hoban et al. (2013a, b).

We also have preliminary data on multiplexes for use in roan antelope, eland and gemsbok. More samples are needed from a wider range of game ranches (and open systems) to evaluate these microsatellite markers. The laboratory receives small numbers of samples from blesbok (Damaliscus pygargus phillipsi), bontebok (D. p. pygarus), bushbuck (Tragelaphus sylvaticus), red hartebeest (Alcelaphus buselaphus caama), greater kudu ( $T$. strepsiceros), nyala ( $T$. angasii), reedbuck (Redunca sp.), springbok (Antidorcas marsupialis), waterbuck (Kobus ellipsiprymnus) and black wildebeest (Connochaetes gnou). Early testing indicates that many of the microsatellite markers we are using in the more common species will also be applicable to these species.

We have secured private funding for blue wildebeest and impala genome sequencing for another purpose. The sable antelope genome has recently been sequenced by a team in the US (pers. comm. 
Klaus-Peter Koepfli). We will then be able to mine the genomes in silico using software such as GMATo (Genome Microsatellite Analyzing Tool) (Wang et al. 2013) or Phobos (Mayer 2006) for more robust microsatellite markers such as tetranucleotide repeats within these species. This will be particularly useful for the blue wildebeest which appears to need more informative microsatellite markers most urgently. In addition, a 2015 publication has identified 57 microsatellite markers in the giant sable antelope (H. n. variani) and tested them in three sub-species of sable and roan antelope (Vaz Pinto et al. 2015). Some of these microsatellite markers may be useful additions to our sable and roan antelope panels and possibly some of the other species.

\section{Conclusions}

The use of microsatellite markers in the wildlife industry in South Africa is critical to ensure the genetic management of these animals. The number of species in the industry and intensive breeding makes this a challenge. We have highlighted the progress in our laboratory so far in both identification of individual animals and parentage assignment. There is still a lot of work to be done to increase the power of these tests and to expand panel optimization to other species. Improvements could be achieved through development of more microsatellite markers, standardised sampling techniques to reduce errors and improved non-genetic data capture and testing of alternative sexing markers in species where the amelogenin marker was unsuccessful. With appropriate reference samples these tests could be applied to hybridisation testing between closely related species or subspecies. Sampling from less intensely managed areas would provide controls to enable population analyses of game ranch herds. This would allow for scientific assessment of the intensively managed herds with respect to their conservation value (including colour variants), as well as the development of policy and management practices within the larger wildlife industry.

\section{Acknowledgements}

The authors thank an anonymous reviewer for constructive comments that improved the manuscript.

\section{References}

ABSA (2016) ABSA Agricultural Outlook 2016. http://agriconnect.co.za/agricultural-outlook/absaagricultural-outlook/agricultural-outlook-digital-edition/book/114.html?page=96\&tmpl=component. Accessed 08 January 2016.

Bernatchez L, Duchesne P (2000) Individual-based genotype analysis in studies of parentage and population assignment: how many loci, how many alleles? Can J Fish Aquat Sci 57:1-12

Brownstein MJ, Carpten JD, Smith JR (1996) Modulation of non-templated nucleotide addition by Taq DNA polymerase: primer modifications that facilitate genotyping. Biotechinques 20:1004-1008.

Goudet J (1995) A computer program to calculate F-statistics. J Hered 86:486 
Grobler JP, Van der Bank FH (1994) Allozyme variation in South African impala populations under different management regimes. S Afr J Wild Res 24:89-94

Grzybowski G, Prusak B, Romaniuk B (2006) A novel variant of the amelogenin gene (AMEL-X) in cattle and its implications for sex determination. Anim Sci P 24:111-118

Harper CK, Vermeulen GJ, Clarke AB, de Wet JI, Guthrie AJ (2013) Extraction of nuclear DNA from rhinoceros horn and characterization of DNA profiling systems for white (Ceratotherium simum) and black (Diceros bicornis) rhinoceros. Forensic Sci Int: Genet 7:428-433

Harris TR, Caillaud D, Chapman CA, Vigilant L (2009) Neither genetic nor observational data alone are sufficient for understanding sex-biased dispersal in a social-group-living species. Mol Ecol 18:1777-1790

Harrison HB, Saenz-Agudelo P, Planes S, Jones GP, Berumen ML (2013) Relative accuracy of three common methods of parentage analysis in natural populations. Mol Ecol 22:1158-1170

Heaton MP, Harhay GP, Bennett GL, Stone RT, Grosse WM, Casas E, Keele JW, Smith TPL, ChitkoMcKown CG, Laegreid WW (2002) Selection and use of SNP markers for animal identification and paternity analysis in U.S. beef cattle. Mamm Genome 13:272-281

Heaton MP, Leymaster KA, Kalbfleisch TS, Kijas JW, Clarke SM, McEwan J, Maddox JF, Basnayake V, Petrik DT, Simpson B, Smith TPL, Chitko-McKown CG, and the International Sheep Genomics Consortium (2014) SNPs for Parentage Testing and Traceability in Globally Diverse Breeds of Sheep. PloS ONE 9:e94851

Hoban S, Arntzen JW, Bertorelle G, Bryja J, Fernandes M, Frith K, Gaggiotti O, Galbusera P, Godoy JA, Hauffe HC, Rus Hoelzel A, Nichols RA, Pérez-Espona S, Primmer C, Russo IR, Segelbacher G, Siegismund HR, Sihvonen M, Sjögren-Gulve P, Vernesi C, Vilà C, Bruford MW (2013a) Conservation Genetic Resources for Effective Species Survival (ConGRESS): Bridging the divide between conservation research and practice. J Nat Conserv 21:433-437

Hoban S, Hauffe H, Pérez-Espona S, Arntzen J, Bertorelle G, Bryja J, Frith K, Gaggiotti O, Galbusera P, Godoy JA, Hoelzel AR, Nichols R, Primmer C, Russo IR, Segelbacher G, Siegismund H, Sihvonen $M$, Vernesi C, Vilà $C$, Bruford $M(2013 b)$ Bringing genetic diversity to the forefront of conservation policy and management. Conserv Genet Resour 5:593-598

Huebinger RM, de Maar TWJ, Woodruff LH, Pomp D, Louis EE (2006) Characterization of nine microsatellite loci in impala (Aepyceros melampus). Mol Ecol Notes 6:1152-1153

IUCN/SSC Antelope Specialist Group (2015) IUCN SSC ASG Position Statement on the Intentional Genetic Manipulation of Antelopes.

http://www.iucn.org/about/work/programmes/species/who_we_are/ssc_specialist_groups_and_red_lis 
t_authorities_directory/mammals/asghome/?21393/position-statement-on-the-intentional-geneticmanipulation-of-antelopes. Accessed 15 October 2015

Jones AG, Small CM, Paczolt KA, Ratterman NL (2010) A practical guide to methods of parentage analysis. Mol Ecol Resour 10:6-30

Kalinowski ST, Taper ML, Marshall TC (2007) Revising how the computer program CERVUS accommodates genotyping error increases success in paternity assignment. Mol Ecol 16:1099-1106

Lindsay A, Belant J (2008) A simple and improved PCR-based technique for white-tailed deer (Odocoileus virginianus) sex identification. Conserv Genet 9:443-447

Lindsey P, Romanach SS, Davies-Mostert HT (2009) The importance of conservancies for enhancing the value of game ranch land for large mammal conservation in southern Africa. J Zool 277:99-105

Luxmoore R (1985) Game farming in South Africa as a force in conservation. Oryx 19:225-231

Mayer C (2006) Phobos, 3.3.11, 2006-2010 <http://www.rub.de/spezzoo/cm/cm_phobos.htm>

Miller SM, Harper CK, Bloomer P, Hofmeyr J, Funston PJ (2014) Evaluation of Microsatellite Markers for Populations Studies and Forensic Identification of African Lions (Panthera leo). J Hered 105:762772. doi:10.1093/jhered/esu054

Narum SR (2006) Beyond Bonferroni: Less conservative analyses for conservation genetics. Conser Genet 7:783-787

Ogden R, Dawnay N, McEwing R (2008) Development of STR profiling systems for individual identification in wildlife: A case study of the Eurasian badger, Meles meles. Forensic Sci Int: Genet Suppl Ser 1:612-613

Ogden R, Dawnay N, McEwing R (2009) Wildlife DNA forensics - bridging the gap between conservation genetics and law enforcement. Endanger Species Res 9:179-195

Peakall R, Smouse PE (2006) GENALEX 6: genetic analysis in Excel. Population genetic software for teaching and research. Mol Ecol Notes 6:288-295

Pemberton JM, Slate J, Bancroft DR, Barrett JA (1995) Nonamplifying alleles at microsatellite loci: a caution for parentage and population studies. Mol Ecol 4:249-252

Rice WR (1989) Analyzing tables of statistical tests. Evolution 43:223-225

Røed KH, Ernest E, Midthjell L, Msoffe P (2011) Identification and characterization of 17 microsatellite loci in the blue wildebeest, Connochaetes taurinus. Conserv Genet Resour 3:181-183

Rousset F (2008) GENEPOP'007: a complete re-implementation of the GENEPOP software for Windows and Linux. Mol Ecol Resour 8:103-106 
SA Hunters and Game Conservation Association (2015) Hunting body calls for regulation of intensive commercial game breeding practices. http://www.sahunters.co.za/index.php/item/184-hunting-bodycalls-for-regulation-of-intensive-commercial-game-breeding-practices. Accessed 15 October 2015.

Selkoe K, Toonen RJ (2006) Microsatellites for ecologists: a practical guide to using and evaluating microsatellite markers. Ecol Lett 9:615-629

SWGWILD (2012) SWGWILD Standards and Guidelines.

http://www.vgl.ucdavis.edu/forensics/documents/swgwild_white_paper_011012.pdf. Accessed 06 June 2015

Thomas S (2013) Game price stampede. African Indaba 11: 20.

http://africanindaba.com/2013/11/south-africa-game-price-stampede-november-2013-volume-11-56/. Accessed 02 February 2015.

Toonen RJ, Hughes S (2001) Increased throughput for fragment analysis on ABI Prism 377 automated sequencer using a membrane comb and STRand software. BioTechniques 31:1324

van Hooft WF, Hanotte O, Wenink PW, Groen AF, Sugimoto Y, Prins HHT, Teale A (1999) Applicability of bovine microsatellite markers for population genetic studies on African buffalo (Syncerus caffer). Anim Genet 30:214-220

van Hooft WF, Groen AF, Prins HHT (2000) Microsatellite analysis of genetic diversity in African buffalo (Syncerus caffer) populations throughout Africa. Mol Ecol 9:2017-2025

Vaz Pinto P, Lopes S, Mourão S, Baptista S, Siegismund H, Jansen van Vuuren B, Beja P, Ferrand N, Godinho R (2015) First estimates of genetic diversity for the highly endangered giant sable antelope using a set of 57 microsatellites. Eur J Wildl Res1-5

Waits LP, Luikart G, Taberlet P (2001) Estimating the probability of identity among genotypes in natural populations: cautions and guidelines. Mol Ecol 10:249-256

Wang X, Lu P, Luo Z (2013) GMATo: A novel tool for the identification and analysis of microsatellites in large genomes. Bioinformation 9:541-544 
Online Resource 1. Primer and multiplexing details for microsatellite loci

\begin{tabular}{|c|c|c|c|c|c|c|}
\hline Locus & Forward Primer & Reverse Primer & Ref & $\begin{array}{c}\text { Nucleotide } \\
\text { repeats }\end{array}$ & $\begin{array}{l}\text { Dye } \\
\text { label }\end{array}$ & Conc \\
\hline \multicolumn{7}{|l|}{ Buffalo } \\
\hline \multicolumn{7}{|c|}{ Multiplex $160^{\circ} \mathrm{C}^{*}$} \\
\hline AMEL & CAGCCAAACCTCCCTCTGC & CCCGCTTGGCTTGTCTGTTGC & [1] & $X Y$ & VIC & 0.10 \\
\hline BM1824 & GAGCAAGGTGTTTTTCCAATC & GTGTCTTCATTCTCCAACTGCTTCCTTG & [2] & $\mathrm{Di}$ & FAM & 0.06 \\
\hline BM4028 & ACGGAAGCAGCATCTCTTAC & GTGTCTTATGGAAACATGGTCTCCTGC & {$[2,3]$} & $\mathrm{Di}^{\mathrm{a}}$ & NED & 0.06 \\
\hline ETH10 & GTTCAGGACTGGCCCTGCTAACA & GTGTCTTCCTCCAGCCCACTTTCTCTTCTC & [4-6] & $\mathrm{Di}$ & NED & 0.08 \\
\hline SPS115 & AAAGTGACACAACAGCTTCTCCAG & GTGTCTTAACGAGTGTCCTAGTTTGGCTGTG & {$[5,7]$} & $\mathrm{Di}^{\mathrm{a}}$ & PET & 0.10 \\
\hline TGLA227 & CGAATTCCAAATCTGTTAATTTGCT & GTGTCTTACAGACAGAAACTCAATGAAAGCA & {$[5,8]$} & $\mathrm{Di}$ & FAM & 0.08 \\
\hline \multicolumn{7}{|c|}{ Multiplex $260^{\circ} \mathrm{C}^{*}$} \\
\hline BM3205 & TCTTGCTTCCTTCCAAATCTC & GTGTCTTTGCCCTTATTTTAACAGTCTGC & {$[2,3]$} & $\mathrm{Di}$ & PET & 0.10 \\
\hline BM3517 & GTGTGTTGGCATCTGGACTG & GTGTCTTTGTCAAATTCTATGCAGGATGG & {$[2,3]$} & $\mathrm{Di}$ & NED & 0.08 \\
\hline INRA006 & AGGAATATCTGTATCAACCTCAGTC & GTGTCTTCTGAGCTGGGGTGGGAGCTATAAATA & [9] & $\mathrm{Di}$ & FAM & 0.12 \\
\hline TGLA057 & GCTTTTTAATCCTCAGCTTGCTG & GTGTCTTGCTTCCAAAACTTTACAATATGTAT & {$[8,10]$} & $\mathrm{Di}$ & VIC & 0.08 \\
\hline TGLA159 & GCATCCAGGGAACAAATTACAAAC & GTGTCTTTTTATTTCGAATCTCTTGAGTACAG & {$[8,10]$} & $\mathrm{Di}$ & VIC & 0.08 \\
\hline \multicolumn{7}{|c|}{ Multiplex $360^{\circ} \mathrm{C}^{*}$} \\
\hline BM719 & TTCTGCAAATGGGCTAGAGG & GTGTCTTCACACCCTAGTTTGTAAGCAGC & {$[2,3]$} & $\mathrm{Di}$ & VIC & 0.08 \\
\hline CSSM19 & TTGTCAGCAACTTCTTGTATCTTT & GTGTCTTTGTTTTAAGCCACCCAATTATTTG & {$[11]$} & $\mathrm{Di}$ & FAM & 0.10 \\
\hline ILSTS026 & CTGAATTGGCTCCAAAGGCC & GTGTCTTAAACAGAAGTCCAGGGCTGC & {$[12]$} & $\mathrm{Di}$ & PET & 0.08 \\
\hline TGLA263 & CAAGTGCTGGATACTATCTGAGCA & GTGTCTTTTAAAGCATCCTCACCTATATATGC & {$[7,10]$} & $\mathrm{Di}$ & PET & 0.10 \\
\hline \multicolumn{7}{|c|}{ Multiplex $460^{\circ} \mathrm{C}$ - added later to increase the power of individual identification } \\
\hline BM1818 & AGCTGGGAATATAACCAAAGG & GTGTCTTGTGTCTTAGTGCTTTCAAGGTCCATGC & {$[2]$} & $\mathrm{Di}$ & PET & 0.06 \\
\hline CSRM60 & AAGATGTGATCCAAGAGAGAGGCA & GTGTCTTAGGACCAGATCGTGAAAGGCATAG & [8] & $\mathrm{Di}$ & PET & 0.10 \\
\hline DIK020 & AACCAGTAATCGTGAGAGGA & GTGTCTTAAGAAAGTCCCTACCATGAG & [13] & $\mathrm{Di}$ & VIC & 0.12 \\
\hline ILSTS028 & GCCTAACTAAGTTATTGAGATGACACA & GTGTCTTAAAATTAGTTCATACCCTTGCATGT & [12] & $\mathrm{Di}$ & NED & 0.06 \\
\hline
\end{tabular}

*Muliplexes 1, 2 and 3 can be combined into one run on the sequencer

${ }^{a}$ contains some single repeats 
Impala

Multiplex $163^{\circ} \mathrm{C}$

1122

114

1206

1264

$1688^{\mathrm{b}}$

1701

1707

19

Multiplex $261^{\circ} \mathrm{C}$

BM1824 GAGCAAGGTGTTTTTCCAATC

ILSTS87 AGCAGACATGATGACTCAGC

TGLA122 AATCACATGGCAAATAAGTACATAC

\section{Multiplex $365^{\circ} \mathrm{C}$}

INRA5

SPS113

TTCAGGCATACCCTACACCACATG

CCTCCACACAGGCTTCTCTGACTT

\section{Multiplex $460^{\circ} \mathrm{C}$}

D5S2

ETH10

TACTCGTAGGGCAGGCTGCCTG

SPS115

GTTCAGGACTGGCCCTGCTAACA

AAAGTGACACAACAGCTTCTCCAG

1688 is no longer included

${ }^{\mathrm{c}}$ TGLA263 has since been moved to Multiplex 4 and changed to VIC at a concentration of 0.10

dprimers have been redesigned by ISAG since original reference

eSPS115 is no longer included and has been replaced by TGLA263
GTGTCTTGACCCAATGACCCAAAACCAT

GTGTCTTAAGGGAAAGGCTGATGCTAC

GTGTCTTCACTCCTGTATTCTGCCTGG

GTGTCTTGTTGCCATGATGTTTTGCTTTG

GTGTCTTGTGTAATCATCAGTCCCCTGTT

GTGTCTTGCGGGCAAGTTCTTTACCAC

GTGTCTTAAGGGGATAGTGATGGAAAGCC

GTGTCTTCTCCTCTCCCTCCCTCTTCC

GTGTCTTCATTCTCCAACTGCTTCCTTG

GTGTCTTCTGCCTCTTTTCTTGAGAG

CCCTCCTCCAGGTAAATCAGC

GTGTCTTAAATATTAGCCAACTGAAAACTGGG

GTGTCTTCCTAACTTGCTTGAGTTATTGCCC

GTGTCTTTTAAAGCATCCTCACCTATATATGC

GTGTCTTGAGACCTCAGGGTTGGTGATCAG

GTGTCTTCCTCCAGCCCACTTTCTCTTCTC GTGTCTTAACGAGTGTCCTAGTTTGGCTGTG

\begin{tabular}{cccc}
{$[14]$} & $\mathrm{Di}$ & VIC & 0.05 \\
{$[14]$} & $\mathrm{Di}$ & PET & 0.10 \\
{$[14]$} & $\mathrm{Di}$ & NED & 0.20 \\
{$[14]$} & $\mathrm{Di}$ & FAM & 0.05 \\
{$[14]$} & $\mathrm{Di}$ & FAM & 0.10 \\
{$[14]$} & $\mathrm{Di}$ & VIC & 0.10 \\
{$[14]$} & $\mathrm{Di}$ & VIC & 0.05 \\
{$[14]$} & $\mathrm{Di}$ & FAM & 0.10 \\
& & & \\
{$[2]$} & $\mathrm{Di}$ & FAM & 0.10 \\
{$[12]$} & $\mathrm{Di}$ & PET & 0.08 \\
{$[2]$} & $\mathrm{Di}$ & NED & 0.08 \\
& & & \\
{$[9]$} & $\mathrm{Di}$ & NED & 0.10 \\
{$[15]$} & $\mathrm{Di}$ & FAM & 0.10 \\
{$[7,10]$} & $\mathrm{Di}$ & PET & 0.10 \\
{$[6]^{\mathrm{d}}$} & $\mathrm{Di}$ & FAM & 0.12 \\
{$[4-6]$} & $\mathrm{Di}$ & NED & 0.1 \\
{$[5,7]$} & $\mathrm{Di}$ & VIC & 0.08 \\
\hline
\end{tabular}


Sable and Roan

Multiplex $162^{\circ} \mathrm{C}$

BM719 TTCTGCAAATGGGCTAGAGG

CT07Gnu CTACCTGGGAAACCCATAT

Multiplex $262^{\circ} \mathrm{C}$

ILSTS087 AGCAGACATGATGACTCAGC

CT03Gnu CCATTCTAATGGGACCCTTG

SPS113 CCTCCACACAGGCTTCTCTGACTT

ETH10 GTTCAGGACTGGCCCTGCTAACA

Multiplex $362^{\circ} \mathrm{C}$

BM2113 GCTGCCTTCTACCAAATACCC

CT13Gnu TTTACCGTCTGAGCCACACA

D5S2

TACTCGTAGGGCAGGCTGCCTG

Multiplex $462^{\circ} \mathrm{C}$

TGLA263 CAAGTGCTGGATACTATCTGAGCA

AMEL CAGCCAAACCTCCCTCTGC

SRCRSP24 AGCAAGAAGTGTCCACTGACAG

CT10Gnu CCTCTTTGCCCTGTTCTTCA

Multiplex $561^{\circ} \mathrm{C}$

CSSM19 TTGTCAGCAACTTCTTGTATCTTT

ILSTS19 AGGGACCTCATGTAGAAGC

BMS4008
GTGTCTTCACACCCTAGTTTGTAAGCAGC

GTGTCTTTGTTGGTTTCTGCCATACAA

GTGTCTTCTGCCTCTTTTCTTGAGAG

GTGTCTTAGCACCCAACGAAACTAACC

GTGTCTTCCTAACTTGCTTGAGTTATTGCCC

GTGTCTTCCTCCAGCCCACTTTCTCTTCTC

CTTCCTGAGAGAAGCAACACC

GTGTCTTCCAGAGCAGAATTTTGAGCA

GTGTCTTGAGACCTCAGGGTTGGTGATCAG

GTGTCTTTTAAAGCATCCTCACCTATATATGC

CCCGCTTGGCTTGTCTGTTGC

GTGTCTTTCTAGGTCCATCTGTGTTATTGC

GTGTCTTGGTATTGGTGACCACCTGCT

GTGTCTTTGTTTTAAGCCACCCAATTATTTG

GTGTCTTACTTTTGGACCCTGTAGTGC

GAAGAGTGTGAGGGAAAGACTG

\begin{tabular}{|c|c|c|c|}
\hline$[2,3]$ & $\mathrm{Di}$ & NED & 0.06 \\
\hline [16] & Di & PET & 0.07 \\
\hline [12] & $\mathrm{Di}$ & FAM & 0.10 \\
\hline [16] & $\mathrm{Di}$ & VIC & 0.10 \\
\hline [15] & $\mathrm{Di}$ & PET & 0.08 \\
\hline [4-6] & $\mathrm{Di}$ & NED & 0.03 \\
\hline [2] & $\mathrm{Di}$ & FAM & 0.8 \\
\hline [16] & $\mathrm{Di}$ & VIC & 0.10 \\
\hline$[6]$ & $\mathrm{Di}$ & FAM & 0.08 \\
\hline$[7,10]$ & $\mathrm{Di}$ & PET & 0.12 \\
\hline$[1]$ & $X Y$ & VIC & 0.03 \\
\hline [17] & $\mathrm{Di}$ & FAM & 0.12 \\
\hline [16] & Di & NED & 0.12 \\
\hline [7] & $\mathrm{Di}$ & FAM & 0.10 \\
\hline [12] & $\mathrm{Di}$ & NED & 0.10 \\
\hline [18] & Di & PET & 0.10 \\
\hline
\end{tabular}


Wildebeest

Multiplex $165^{\circ} \mathrm{C}$

BM2113 GCTGCCTTCTACCAAATACCC

D5S2 TACTCGTAGGGCAGGCTGCCTG

BM719 TTCTGCAAATGGGCTAGAGG

OarFCB20 GGAAAACCCCCATATATACCTATAC

Multiplex $261^{\circ} \mathrm{C}$

SRCRSP24 AGCAAGAAGTGTCCACTGACAG

ILST19 AGGGACCTCATGTAGAAGC

BMS4008 CGGCCCTAAGTGATATGTTG

Multiplex $363^{\circ} \mathrm{C}$

CT07Gnu CTACCTGGGAAACCCATAT

AMEL CAGCCAAACCTCCCTCTGC

Multiplex $461^{\circ} \mathrm{C}$

CT27Gnu AAAAACCACTTAATCTGCAAGGA

CT03Gnu CCATTCTAATGGGACCCTTG

CT12Gnu GATCAATGCTTGCAAATCCA

CT19Gnu AATCACATGCTGCATTTTT

Multiplex $563^{\circ} \mathrm{C}$

CT08Gnu CAGGGTGAAGGAAGTCAGAAA

CT30Gnu AAACTGACAAACCTTTCTCTAGACC

CT13Gnu TTTACCGTCTGAGCCACACA

CT10Gnu CCTCTTTGCCCTGTTCTTCA

CTTCCTGAGAGAAGCAACACC

GTGTCTTGAGACCTCAGGGTTGGTGATCAG

GTGTCTTCACACCCTAGTTTGTAAGCAGC

GTGTCTTAAATGTGTTTAAGATTCCATACATGTG

$\begin{array}{cccc}{[2]} & \mathrm{Di} & \text { FAM } & 0.07 \\ {[6]} & \mathrm{Di} & \text { FAM } & 0.08 \\ {[2,3]} & \mathrm{Di} & \text { NED } & 0.1 \\ {[19]} & \mathrm{Di} & \text { PET } & 0.15\end{array}$

GTGTCTTTCTAGGTCCATCTGTGTTATTGC

[17]

GTGTCTTACTTTTGGACCCTGTAGTGC

GAAGAGTGTGAGGGAAAGACTG

[12]

[18]

[16] Di $\quad$ PET $\quad 0.1$

GTGTCTTTGTTGGTTTCTGCCATACAA

CCCGCTTGGCTTGTCTGTTGC

VIC

0.05

GTGTCTTAAATAGGTGGGTGCCGTGT

GTGTCTTAGCACCCAACGAAACTAACC

GTGTCTTGACAGGCAAACAGTGATTGAAA

GTGTCTTGGAGAGAAGGGAAAGGGTTC

[16]

[16]

[16]

[16]

[16]

GTGTCTTGGGTCACCATTACCACCTTTT

GTGTCTTTGTCCCTCTGCATTTCTGTG

GTGTCTTCCAGAGCAGAATTTTGAGCA

GTGTCTTGGTATTGGTGACCACCTGCT
[16]

[16]

[16] $\begin{array}{ll} & \\ \text { FAM } \quad 0.07\end{array}$

VIC $\quad 0.08$

NED $\quad 0.07$

PET $\quad 0.1$

FAM $\quad 0.07$

VIC $\quad 0.05$

VIC $\quad 0.1$

NED $\quad 0.08$ 
Eland

Multiplex $162^{\circ} \mathrm{C}$

SPS113 CCTCCACACAGGCTTCTCTGACTT

ETH10 GTTCAGGACTGGCCCTGCTAACA

17 GCGTGCCATTTCCTTCATGG

1701 ACTCTTCTGGCTCAAATAATACTGC

Multiplex $262^{\circ} \mathrm{C}$

1122

CAGCGTACCCTTCAGAAGCA

SRCRSP5 GGACTCTACCAACTGAGCTACAAG

INRA005 TTCAGGCATACCCTACACCACATG

D5S2

TACTCGTAGGGCAGGCTGCCTG

Multiplex $362^{\circ} \mathrm{C}$

INRA006

AGGAATATCTGTATCAACCTCAGTC

CT03Gnu

CCATTCTAATGGGACCCTTG

TGLA122

ILSTS87

AATCACATGGCAAATAAGTACATAC

INRA023

AGCAGACATGATGACTCAGC

GAGTAGAGCTACAAGATAAACTTC

GTGTCTTCCTAACTTGCTTGAGTTATTGCCC

$\begin{array}{cccc}{[15]} & \mathrm{Di} & \text { FAM } & 0.06 \\ {[4-6]} & \mathrm{Di} & \text { NED } & 0.06 \\ {[14]} & \mathrm{Di} & \text { NED } & 0.06 \\ {[14]} & \mathrm{Di} & \text { VIC } & 0.06 \\ & & & \\ {[14]} & \mathrm{Di} & \mathrm{VIC} & 0.06 \\ {[20]} & \mathrm{Di} & \text { VIC } & 0.06 \\ {[9]} & \mathrm{Di} & \mathrm{NED} & 0.06 \\ {[6]} & \mathrm{Di} & \text { FAM } & 0.06 \\ & & & \\ {[9]} & \mathrm{Di} & \text { FAM } & 0.08 \\ {[16]} & \mathrm{Di} & \mathrm{VIC} & 0.05 \\ {[2]} & \mathrm{Di} & \mathrm{NED} & 0.06 \\ {[12]} & \mathrm{Di} & \text { PET } & 0.06\end{array}$

GTGTCTTAGGTACACAGGAGACAGGCA

GTGTCTTGCGGGCAAGTTCTTTACCAC

GTGTCTTGACCCAATGACCCAAAACCAT

GTGTCTTTGAAATGAAGCTAAAGCAATGC

GTGTCTTAAATATTAGCCAACTGAAAACTGGG

GTGTCTTGAGACCTCAGGGTTGGTGATCAG

GTGTCTTCTGAGCTGGGGTGGGAGCTATAAATA

GTGTCTTAGCACCCAACGAAACTAACC

CCCTCCTCCAGGTAAATCAGC

GTGTCTTCTGCCTCTTTTCTTGAGAG

GTGTCTTTAACTACAGGGTGTTAGATGAACTC

[21]

VIC

0.08 
Gemsbok

Multiplex $165^{\circ} \mathrm{C}$

SPS113 CCTCCACACAGGCTTCTCTGACTT

TGLA263 CAAGTGCTGGATACTATCTGAGCA

ILST19 AGGGACCTCATGTAGAAGC

BM3517 GTGTGTTGGCATCTGGACTG

Multiplex $261^{\circ} \mathrm{C}$

CSSM19 TTGTCAGCAACTTCTTGTATCTTT

BMS4008 CGGCCCTAAGTGATATGTTG

CT10Gnu CCTCTTTGCCCTGTTCTTCA

Multiplex $363^{\circ} \mathrm{C}$

ILSTS87 AGCAGACATGATGACTCAGC

CSSM66 AATTTAATGCACTGAGGAGCTTGG

SPS115 AAAGTGACACAACAGCTTCTCCAG

BM719 TTCTGCAAATGGGCTAGAGG

Multiplex $461^{\circ} \mathrm{C}$

BM2113 GCTGCCTTCTACCAAATACCC

ETH3 GAACCTGCCTCTCCTGCATTGG

D5S2 TACTCGTAGGGCAGGCTGCCTG

1707 ATTCCCTGGCCACTGTCTTG

AMEL CAGCCAAACCTCCCTCTGC

GTGTCTTCCTAACTTGCTTGAGTTATTGCCC GTGTCTTTTAAAAGCATCCTCACCTATATATGC GTGTCTTACTTTTGGACCCTGTAGTGC GTGTCTTTGTCAAATTCTATGCAGGATGG

GTGTCTTTGTTTTAAGCCACCCAATTATTTG

GAAGAGTGTGAGGGAAAGACTG

GTGTCTTGGTATTGGTGACCACCTGCT

GTGTCTTCTGCCTCTTTTCTTGAGAG

GTGTCTTACACAAATCCTTTCTGCCAGCTGA

GTGTCTTAACGAGTGTCCTAGTTTGGCTGTG GTGTCTTCACACCCTAGTTTGTAAGCAGC

CTTCCTGAGAGAAGCAACACC

GTGTCTTACTCTGCCTGTGGCCAAGTAGG

GTGTCTTGAGACCTCAGGGTTGGTGATCAG

GTGTCTTAAGGGGATAGTGATGGAAAGCC

CCCGCTTGGCTTGTCTGTTGC

$\begin{array}{cccc}{[15]} & \mathrm{Di} & \text { FAM } & 0.07 \\ {[7]} & \mathrm{Di} & \text { PET } & 0.07 \\ {[12]} & \mathrm{Di} & \text { NED } & 0.10 \\ {[2,3]} & \mathrm{Di} & \text { NED } & 0.12 \\ & & & \\ {[7]} & \mathrm{Di} & \text { FAM } & 0.13 \\ {[18]} & \mathrm{Di} & \text { PET } & 0.13 \\ {[16]} & \mathrm{Di} & \text { NED } & 0.10 \\ & & & \\ {[12]} & \mathrm{Di} & \text { PET } & 0.20 \\ {[8]} & \mathrm{Di} & \text { FAM } & 0.05 \\ {[5,7]} & \mathrm{Di} & \text { VIC } & 0.07 \\ {[2,3]} & \mathrm{Di} & \text { NED } & 0.03 \\ & & & \\ {[2]} & \mathrm{Di} & \text { FAM } & 0.10 \\ {[6]} & \mathrm{Di} & \text { PET } & 0.10 \\ {[6]} & \mathrm{Di} & \text { FAM } & 0.10 \\ {[14]} & \mathrm{Di} & \text { VIC } & 0.10 \\ {[1]} & \mathrm{XY} & \text { VIC } & 0.10\end{array}$




\section{References}

(1) Gryzbowski G, Prusak B, Romaniuk B (2006) A novel variant of the amelogenin gene (AMEL-X) in cattle and its implications for sex determination. Anim Sci Pap Rep 24: 111-118.

(2) Bishop MD, Kappes SM, Keele JW, Stone RT, Sunden SLF, et al. (1994) A genetic linkage map for cattle. Genetics 136: 619-639.

(3) van Hooft WF, Hanotte O, Wenink PW, Groen AF, Sugimoto Y, et al. (1999) Applicability of bovine microsatellite markers for population genetic studies on African buffalo (Syncerus caffer). Anim Genet 30: 214-220.

(4) Luikart G, Biju-Duval MP, Ertugrul O, Zagdsuren Y, Maudet C, et al. (1999) Power of 22 microsatellite markers in fluorescent multiplexes for parentage testing in goats (Capra hircus). Anim Genet 30: 431-438.

(5) Greyling BJ, Kryger P, du Plessis S, van Hooft WF, van Helden P, et al. (2008) Development of a high-throughput microsatellite typing approach for forensic and population genetic analysis of wild and domestic African Bovini. Afr J Biotech 7: 655-660.

(6) Toldo SS, Fries R, Steffen P, Neibergs HL, Barendse W, et al. (1993) Physically mapped, cosmid-derived microsatellite markers as anchor loci on bovine chromosomes. Mamm Genome 4: 720-727.

(7) Mommens G, Van Zeveren A, Peelman L (1998) Effectiveness of bovine microsatellites in resolving paternity cases in American bison, Bison bison L. Anim Genet 29: 12-18.

(8) Barendse W, Armitage SM, Kossarek LM, Shalom A, Kirkpatrick BW, et al. (1994) A genetic linkage map of the bovine genome. Nature Genet 6: 277235.

(9) Vaiman D, Osta R, Mercier D, Grohs C, Leveziel H (1992) Characterization of five new bovine dinucleotide repeats. Anim Genet 23: 537-541.

(10) van Hooft WF, Groen AF, Prins HHT (2000) Microsatellite analysis of genetic diversity in African buffalo (Syncerus caffer) populations throughout Africa. Mol Ecol 9: 2017-2025.

(11) Moore SS, Byrne K, Berger KT, Barendse W, McCarthy F, et al. (1994) Characterization of 65 bovine microsatellites. Mamm Genome 5: 84-90.

(12) Kemp SJ, Hishida O, Wambugu J, Rink A, Longeri ML, et al. (1995) A panel of polymorphic bovine, ovine and caprine microsatellite markers. Anim Genet 26: 299-306. 
(13) Inoue M, Hirano T, Nakane S, Watanabe T, Takeda H, et al. (1995) Five bovine polymorphic dinucleotide microsatellite loci (DIK008, DIK010, DIK015, DIK016 and DIKO2O). Anim Genet 26: 447a-448.

(14) Huebinger RM, DE MAAR TWJ, WOODRUFF LH, POMP DANI, Louis EE (2006) Characterization of nine microsatellite loci in impala (Aepyceros melampus). Mol Ecol Notes 6: 1152-1153.

(15) Roeder AD, Marshall RK, Mitchelson aJ, Visagathilagar T, Ritchie PA, et al. (2001) Gene flow on the ice: genetic differentiation among Ad+»-+-+lie penguin colonies around Antarctica. Mol Ecol 10: 1645-1656.

(16) Roed KH, Ernest E, Midthjell L, Msoffe P (2011) Identification and characterization of 17 microsatellite loci in the blue wildebeest, Connochaetes taurinus. Conserv Genet Resour 3: 181-183.

(17) Yeh CC, Kogi JK, Holder MT, Guerra TM, Davis SK, et al. (1997) Caprine microsatellite dinucleotide repeat polymorphisms at the SR-CRSP-21, SRCRSP-22, SR-CRSP-23, SR-CRSP-24, SR-CRSP-25, SR-CRSP-26 and SR-CRSP-27 loci. Anim Genet 28: 380-381.

(18) Kappes SM, Keele JW, Stone RT, McGraw RA, Sonstegard TA, et al. (1997) A second-generation linkage map of the bovine genome. Genome Res 7: 235-249.

(19) Buchanan FC, Galloway SM, Crawford AM (1994) Ovine microsatellites at the OarFCB5, OarFCB19, OarFCB20, OarFCB48, OarFCB129 and OarFCB226 loci. Anim Genet 25: 60.

(20) Arevalo E, Holder DA, Derr JN, Bhebhe E, Linn RA, et al. (1994) Caprine microsatellite dinucleotide repeat polymorphisms at the SR-CRSP-1, SR-CRSP2, SR-CRSP-3, SR-CRSP-4 and SR-CRSP-5 loci. Anim Genet 25: 202.

(21) Vaiman D, Imam-Ghali M, Moazami-Goudarzi K, Guerin G, Grohs C, et al. (1994) Conservation of a syntenic group of microsatellite loci between cattle and sheep. Mamm Genome 5: 314. 